\title{
Author Correction: Differential Assessment of Factor Xa Activity and Global Blood Coagulability Utilizing Novel Dielectric Coagulometry
}

\author{
Satomi Hamada ${ }^{1,2}$, Yuki Hasegawa ${ }^{1}$, Ai Oono ${ }^{1}$, Anna Suzuki ${ }^{1,7}$, Naomi Takahashi ${ }^{1,7}$, \\ Takuro Nishimura ${ }^{3}$, Takatoshi Koyama ${ }^{4}$, Michio Hagihara ${ }^{2}$, Shuji Tohda ${ }^{2}$, Tetsushi Furukawa ${ }^{5}$, \\ Kenzo Hirao ${ }^{6}$ \& Tetsuo Sasano ${ }^{1,7}$
}

Correction to: Scientific Reports https://doi.org/10.1038/s41598-018-34229-6, published online 31 October 2018

In this Article the Competing Interests section was omitted. This should read:

“T.S. received research funding from Sony IP\&S Inc."

(c) (i) Open Access This article is licensed under a Creative Commons Attribution 4.0 International cc. License, which permits use, sharing, adaptation, distribution and reproduction in any medium or format, as long as you give appropriate credit to the original author(s) and the source, provide a link to the Creative Commons license, and indicate if changes were made. The images or other third party material in this article are included in the article's Creative Commons license, unless indicated otherwise in a credit line to the material. If material is not included in the article's Creative Commons license and your intended use is not permitted by statutory regulation or exceeds the permitted use, you will need to obtain permission directly from the copyright holder. To view a copy of this license, visit http://creativecommons.org/licenses/by/4.0/.

(C) The Author(s) 2019

\footnotetext{
${ }^{1}$ Department of Biofunctional Informatics, Tokyo Medical and Dental University (TMDU), Tokyo, Japan. ${ }^{2}$ Department of Clinical Laboratory, Medical Hospital, Tokyo Medical and Dental University (TMDU), Tokyo, Japan. ${ }^{3}$ Heart Rhythm Centre, Tokyo Medical and Dental University (TMDU), Tokyo, Japan. ${ }^{4}$ Department of Laboratory Molecular Genetics of Haematology, Tokyo Medical and Dental University (TMDU), Tokyo, Japan. ${ }^{5}$ Department of Bio-informational Pharmacology, Medical Research Institute, Tokyo Medical and Dental University (TMDU), Tokyo, Japan. ${ }^{6}$ Department of Cardiovascular Medicine, Tokyo Medical and Dental University (TMDU), Tokyo, Japan. ${ }^{7}$ Department of Cardiovascular Physiology, Tokyo Medical and Dental University (TMDU), Tokyo, Japan. Correspondence and requests for materials should be addressed to T.S. (email: sasano.bi@tmd.ac.jp)
} 